(2) OPEN ACCESS

${ }^{1}$ Department of Public and Occupational Health, Amsterdam UMC - University of Amsterdam, Amsterdam, The Netherlands

${ }^{2}$ Department of Health

Promotion, Maastricht University, Maastricht, The

Netherlands

${ }^{3}$ Netherlands Expertise Center for Tobacco Control, Trimbos Institute, Utrecht, The Netherlands

Correspondence to Dr Mirte A G Kuipers, Department of Public and Occupational Health, Amsterdam UMC - University of Amsterdam, PO Box 22660 1100 DD Amsterdam, The Netherlands;

m.a.kuipers@amsterdamumc.nl

Received 8 May 2020

Revised 23 December 2020

Accepted 28 December 2020

Check for updates

(c) Author(s) (or their employer(s)) 2021. Re-use permitted under CC BY-NC. No commercial re-use. See rights and permissions. Published by BMJ.

To cite: Kuipers MAG, Nuyts PAW, Willemsen MC, et al. Tob Control Epub ahead of print: [please include Day Month Year]. doi:10.1136/ tobaccocontrol-2020-055910

\title{
Tobacco retail licencing systems in Europe
}

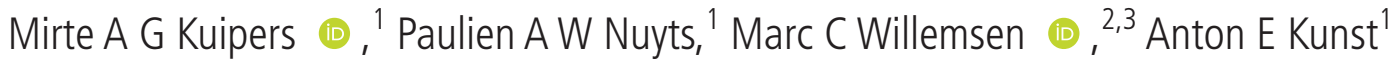

\begin{abstract}
Tobacco retailer licencing has been recommended as an effective tobacco control strategy. In most European countries, however, retailers do not need a licence to sell tobacco products. We aimed to stimulate a discussion on the potential for tobacco retail licencing in Europe by describing (1) potential public health benefits, (2) licencing methods and (3) barriers and success factors in adoption of licencing systems. There is limited scientific evidence, but tobacco retail licencing may reduce smoking in three ways: (1) improved enforcement of and compliance to existing point-of-sale tobacco control policies (eg, minimum age of sale), (2) a reduction in the number and/or density of tobacco retail outlets and (3) denormalisation of tobacco. Licencing systems may take diverse forms. Systems may make licences expensive, and set criteria for purchasing a licence and retaining the licence after first purchase. In Europe, licencing systems have been implemented in Finland, Hungary, France, Italy and Spain. Licencing in Finland and Hungary was adopted for public health reasons; in Finland, with strong public support. In France, Italy and Spain, tobacco sales were state-monopolised, driven by economic motives. The cases of Norway and Scotland show that adoption of retail licencing may fail when political support is insufficient and tobacco retailers organise opposition with support from the tobacco industry. In conclusion, tobacco retailer licencing is a promising method to contribute to tobacco control efforts. Placing tobacco retailer licencing in a child protection framework may help generate the strong political and public support needed to effectively adopt licencing systems.
\end{abstract}

Tobacco retailer licencing has been proposed in the scientific literature ${ }^{1-3}$ and recommended by the WHO as an important tobacco control strategy. ${ }^{4}$ In most European countries, however, retailers do not need a licence to sell tobacco products. In this communication, we seek to stimulate discussion on the potential for tobacco retail licencing in Europe and provide a framework for this discussion. We describe (1) potential benefits of tobacco retail licencing for public health, (2) which licencing systems may be adopted and (3) barriers and success factors in the adoption of licencing systems in Europe. We formulate implications for widerscale adoption of licencing systems in the European setting, which may also provide lessons for settings outside Europe. Our main aim is to encourage a discussion of tobacco retail licencing adoption across the world.

\section{POTENTIAL IMPACTS OF LICENCING SYSTEMS}

We define tobacco retail licencing as a system which obliges all retailers to purchase a special licence in order to be able to legally sell tobacco products. ${ }^{3} \mathrm{We}$ do not discuss 'passive' systems in which tobacco retailers are merely registered or are prohibited from selling tobacco as a sanction for violating other tobacco control policies (eg, sales to minors).

Licencing has potentially large public health benefits by contributing to the prevention of smoking initiation and support of smoking cessation. First, it may increase effective enforcement of existing point-of-sale tobacco control policies, including age-of-sale laws, bans on the display or promotion of tobacco products, taxation and minimum price laws in three ways. First, licences make compliance checks more efficient as there is a complete register of all tobacco retailers in a jurisdiction and the licence offers a point of contact. ${ }^{56}$ Second, licences act as a lever of control for enforcement as retailers may be incentivised to comply with tobacco control policies in order to avoid having their licence suspended or revoked. ${ }^{3}$ Third, licencing fees may raise revenue for tobacco control, which can cover the costs of enforcement activities.

Second, licencing systems may improve public health by reducing the number of tobacco outlets. After implementing licencing systems, the number of outlets was reduced by $28 \%$ in Finland (Timberlake D, 2019, written communication, $28^{\text {th }}$ February), $31 \%$ in a populous California county ${ }^{7}$ and $83 \%$ in Hungary. ${ }^{68}$ In Australia (state of South Asutralia), increasing the licence fee from 13 to 200 AUS\$ decreased the number of retailers by $23.7 \% .^{9}$ In the USA, the number of purchased retail licences decreased $8 \%$ in San Francisco ${ }^{10}$ and 9.8\% in Philadelphia after additional requirements for purchasing a licence were implemented. ${ }^{11}$ Studies found evidence to suggest that lower tobacco outlet density was associated with more favourable smoking outcomes among adolescents ${ }^{12} 13$ and adults, ${ }^{14-16}$ and potentially with lower e-cigarette use. ${ }^{17} 18$ There is little empirical evidence for the effect of tobacco licencing on smoking behaviours, but one study from California observed that adolescent smoking initiation was less likely in communities with stronger tobacco retail licencing regulations compared with weaker licencing. ${ }^{19}$

Third, regulating where tobacco is sold and reducing the visibility of tobacco products in the retail environment may contribute to the denormalisation of tobacco. Stricter regulations of tobacco sales may communicate to the public that tobacco products are not like ordinary consumer products, but are much more harmful. ${ }^{1}$ Such denormalisation of tobacco products and the tobacco industry contributes to smoking prevention and cessation. ${ }^{20}$

\section{Types of licencing systems}

Table 1 summarises methods that may be used within tobacco licencing systems. We distinguish three main categories of methods to ultimately 


\section{Table 1 Possible methods in tobacco retail licencing}

\begin{tabular}{ll}
\hline Method & Explanation \\
\hline $\begin{array}{l}\text { Increase the cost of selling tobacco } \\
\text { Aigh price }\end{array}$ & $\begin{array}{l}\text { A licence would be expensive for retailers. } \\
\text { Retailers pay an additional fee to cover costs of } \\
\text { monitoring for compliance. } \\
\text { Requirement of regular renewal of the licence, for } \\
\text { which retailers have to pay a renewal fee. }\end{array}$ \\
\hline High fines for selling tobacco without a licence & $\begin{array}{l}\text { Retailers pay a high fine for selling tobacco witho } \\
\text { a licence. }\end{array}$ \\
\hline Criteria to purchase licence & $\begin{array}{l}\text { Retailers are only allowed to buy a licence if they } \\
\text { are located at a minimum distance from a school. }\end{array}$ \\
\hline Minimum distance to schools & $\begin{array}{l}\text { Retailers are only allowed to buy a licence if they } \\
\text { are located a minimum distance from an existing } \\
\text { tobacco retail outlet. The distance may depend on } \\
\text { the population. }\end{array}$
\end{tabular}

\section{Potential impact*}

A high price for a licence, a supervision fee and a renewal fee make selling tobacco less attractive and less affordable for retailers. Fewer retailers buy a licence which may decrease the total number of tobacco retail outlets.

Fines discourage illegal tobacco sales and thereby support potential reductions in the number of tobacco retailers.

The average proximity of tobacco retail outlets to schools increases. This would decrease outlet density around schools. Retailers could relocate towards areas without schools, which would not reduce the total number of tobacco retail outlets.

Impact depends on the set distance. This may reduce the number of tobacco retail outlets in areas where the density was high (eg, city centres). In areas where density was low the impact may be minimal. Retailers could move towards lower density areas, which would not result in reducing the total number of tobacco retail outlets.

Licence only available for specific type of retailer

Tobacco licences are only sold to a specific type of retailer, for example, to tobacconists.
Restriction by retailer type may reduce the total number of tobacco retail outlets. There is a risk that shops will adapt their business to adhere to the definition of tobacconist.
Restricted number of licences based on population/area
Total number of available licences restricted to allow a maximum number of retailers per population and/ or per surface area.

\section{Methods of distributing restricted number of licences}

First-come-first-serve

Lottery

Auction
Licences are given out to the first $\mathrm{N}$ retailers annually on a set date.

Licences are raffled to retailers that enter an annual state-organised lottery. After the first round, only licences of retailers that have stopped selling tobacco may be raffled.

Licences are sold to the highest bidder in an annual state-organised auction. After the first round, only licences of retailers that have stopped selling tobacco may be auctioned.

$\begin{array}{lll}\begin{array}{l}\text { Criteria to retain licence } \\ \text { Regular renewal }\end{array} & \begin{array}{l}\text { Requirement of regular renewal of the licence, for } \\ \text { example, annually. }\end{array} & \begin{array}{l}\text { Regular renewal would add to the retailer burden for sales of } \\ \text { tobacco. }\end{array} \\ \text { Compliance with point-of-sale tobacco control policies } & \begin{array}{l}\text { Licence revoked when policies such as age-of-sale } \\ \text { and display ban are violated, or after a set number } \\ \text { of violations. }\end{array} & \begin{array}{l}\text { Compliance and may decrease the total number of tobacco } \\ \text { outlets. }\end{array}\end{array}$

*'Potential impact' describes the effect the licencing method may have on public health through a reduction in tobacco retail outlets.

reduce the number of retailers through licencing: increasing the cost of selling tobacco, applying limiting criteria for purchasing a licence and applying criteria to retain a licence. A licencing system can increase the cost of selling tobacco by making a licence expensive, asking a high renewal fee and adding a monitoring fee to cover enforcement costs. Several criteria may be applied to the purchase of a licence. Retailers may be required to be located a certain distance from schools or from other tobacco outlets. Other options include restricting sales to specific retailer types (eg, only tobacconists) or to limit the total available number of licences granted in an area. In the latter case, licences may for example be sold on a first-come-first-serve basis, through lottery or auction. Lastly, the system may specify how retailers may retain or lose their tobacco licence. Regular renewal can be required, for example, on an annual basis. The licence may be revoked and sales by that retailer prohibited if other tobacco control policies are violated, such as selling tobacco to minors.

Table 1 provides an overview of potential ways in which each method may affect the number of tobacco retail outlets. There is no evidence on how each method, or combination of methods, may be more or less effective than others in reducing the number of outlets. In general, more restrictive licencing systems may have a larger impact on reducing the number of tobacco retailers, and therefore on adolescent and adult smoking, than more open forms of licencing. In order for any licencing system to be effective, sufficient enforcement mechanisms need to be in place to ensure retailers are not selling without a licence.

\section{Tobacco retail licencing in Europe}

In Europe, licencing systems have been implemented in Finland, Hungary, France, Italy and Spain. Finland implemented its licencing system in April 2009. Retailers have to apply and submit an annual self-monitoring plan, pay a licencing fee (determined at the municipal level, ranging from $€ 100$ to $€ 180$ ), pay a supervision fee of $€ 500$ and renew their licence. 5621

In July 2013, Hungary implemented the most restrictive licencing system in Europe. Retailers were required to submit 
an application, write a business plan and pay a licence fee, after which licences were auctioned. ${ }^{8}$ Selling tobacco without a licence can result in fines up to US\$2.2 million, depending on retailer revenue. ${ }^{8}$ The number of available licences in a region or city depends on its population size, with one licence permitted per 2000 residents. ${ }^{56}$

In France, Italy and Spain, tobacco sales are monopolised by the national government. ${ }^{52}$ State-monopolies stem from the colonial age and laws for state-monopolies have been adopted in 1816 in France, 1887 in Spain and 1927 (in its current form) in Italy. ${ }^{23-25}$ In France, retailers have to meet a number of personal and business criteria. ${ }^{23}$ In Italy, tobacco retailers are to keep a minimum distance from one another, dependent on the municipality (eg, 300 metres between retailers in municipalities with a population of 30000 or less). ${ }^{26}$ Spain adopted a nationwide minimum distance in 1998. The number of available licences depends on the volume of sales in the area and the distance to other tobacco retailers (minimum of 150 metres). ${ }^{22}$ In Spain licences are auctioned.

Countries have had different motives for implementing tobacco retail licencing systems. The wish to improve public health in Finland and Hungary is associated with relatively strict licencing systems. ${ }^{27}$ Hungary specifically aimed at preventing adolescent smoking and reducing the number of tobacco outlets, ${ }^{8}$ and Finland aimed at reducing illegal sales of tobacco to minors. ${ }^{5}$ In contrast, France, Italy and Spain mainly aimed at increasing government profit from the sales of tobacco. In Spain, an additional motive was to regulate competition between retailers through setting a minimum distance between retailers. ${ }^{22}$

As presented in the section on impacts of licencing systems, tobacco retail licencing in Hungary and Finland substantially reduced the number of tobacco retail outlets. For the licencing systems of France, Italy and Spain there is no direct empirical evidence for their effects on retail outlet reduction or smoking outcomes. From indirect evidence we may conclude that these systems did not contribute to smoking prevention. According to tobacco control experts from Italy and Spain there was a 3.5\% decline in the number of tobacco control outlets in Italy between 2012 and 2016 and and a 4.1\% decline in outlets in Madrid between 2014 and $2020 .^{28}$ These are smaller reductions than were found in Finland and Hungary. There are also no clear indications that tobacco use was affected, as adult and adolescent smoking prevalence is not lower in France, Italy and Spain than in other European countries. ${ }^{29}$ Moreover, in 2017, Italian adolescents reported to have easy access to cigarettes; $23.8 \%$ of adolescent smokers bought cigarettes in a shop compared with $21.4 \%$ in Portugal and $3.3 \%$ in Finland. ${ }^{30}$ Based on this evidence, we may conclude that the way in which licencing systems were implemented in France, Italy and Spain, that is, driven by economic rather than public health motives, may not be effective in substantially reducing tobacco consumption in the longer term.

\section{Experiences with adoption in Europe}

Very few countries in Europe have adopted a licencing system. In this section we explore what drives or hinders adoption. In particular, we discuss the adoption process in Finland and Hungary, and why adoption failed in Norway and Scotland. Adoption in France, Italy and Spain is not discussed in depth, as these are longstanding state-monopolies whose adoption of licencing does not provide lessons for $21^{\text {st }}$ century Europe. We consider adoption and implementation of tobacco retail licencing at the national level, as this is the most likely scenario for Europe, although some larger countries with more autonomous regions may apply similar adoption strategies at lower levels.

Hungary successfully adopted and implemented a licencing system despite opposition from civil society and tobacco retailers. ${ }^{8}$ Opposition was particularly strong due to the nontransparent selection of retailers granted a licence, in which the government was accused of nepotism. ${ }^{8}$ Although strong political will has been identified as the main success factor in overhauling the retail sector when implementing the licencing system in Hungary, ${ }^{8}$ this strength resulted from an autocratic rather than democratic approach.

In Finland, the adoption of licencing has been positioned within the context of the aim of a smoke-free Finland by 2030, which is defined as reaching $<5 \%$ smoking prevalence across subgroups within one generation. ${ }^{521}$ The adoption of a licencing system was specifically framed to protect children from taking up smoking. In general, there has been strong political and societal support for tobacco control policies in Finland over the last decades.

Some other countries have considered tobacco licencing, but failed to adopt it. In Norway, a licencing system was proposed in 2013 as a means of improving enforcement of age-of-sale laws. ${ }^{31}$ Adoption was hindered by strong opposition from retailers and the instalment of a new government shortly after. ${ }^{5}$ It was reported in 2014 that the new government might choose a 'less bureaucratic solution' such as a registration system. ${ }^{5}$ In 2017, Norway implemented a national registration system. In some municipalities, retailers pay a registration fee, and retailers selling tobacco without a licence may be fined or banned from selling tobacco (Sæbø G, 2020, personal communication, $26^{\text {th }}$ October). In Scotland similar issues were faced in 2007. The tobacco industry strongly opposed the licencing system, spread misinformation and encouraged retailers to speak out against the proposed policy. The arguments were mostly focussed on the financial loss that retailers would suffer, especially if they could not meet all criteria to obtain a licence (eg, distance to schools or other retailers). ${ }^{28}$ According to experts, the tobacco industry actively lobbied to turn members of parliament against licencing. ${ }^{28}$ The Scottish government also chose a registration system instead of a licencing system, in order to limit the burden on local authorities as well as retailers, as retailers had to provide less information for a register and no payments were involved. ${ }^{5}$ The bureaucratic burden for the authorities was not a barrier for adoption in Finland and Hungary as the licence fee covers the administrative costs and includes a supervision fee.

\section{Prospects for future adoption in Europe}

Previous cases demonstrate that having sufficient political support is a prerequisite for adoption of a tobacco retail licensure policy. Political support was strong in Finland, while it was insufficient in Norway and Scotland due to perceived high bureaucratic burden of licencing. Societal support has also contributed to adoption in Finland. Framing licencing as a way to protect children from the harms of tobacco could improve political support, as was the case in Finland. ${ }^{27} 32$ Smoke-free generation goals have been set in at least five European countries including Scotland, Ireland, the Netherlands and Belgium. ${ }^{33}$ The potential for adopting tobacco retailer licencing, when framed in the context of such goals, may be particularly high in these countries.

In order to increase poltical support, it will be important for advocates to emphasise the public health benefits of tobacco retail licencing, including the improved enforcement of existing 
tobacco control policies to prevent sales to minors, as well as enhanced monitoring of other retail tobacco control regulations. Besides these public health benefits, there may be financial benefits that appeal to politicians. These may include a lower risk of tax evasion and illegal tobacco sales or smuggling, and a potential source of income for enforcement of other regulations at the point-of-sale (eg, advertising regulations for other products). Emphasising that the sale of other harmful products (eg, alcohol, gambling items) and other types of services (eg, physicians, hairdressers) require a licence, while a deadly product currently does not, highlights the incongruity of not licencing tobacco retailers.

Dealing with retailer opposition is challenging as opposition may be orchestrated by the tobacco industry and involving tobacco retailers in the policymaking process may delay and dilute policies. ${ }^{3435}$ Offering financial or other types of incentives (business consultations, other resources) to retailers to discontinue tobacco sales may be one way to reduce opposition and at the same time potentially speed up the reduction of the number of tobacco retail outlets. ${ }^{36}$

Experiences outside Europe may provide additional insights. Adoption of local tobacco retail licencing in California was supported by adoption campaigns. ${ }^{37}$ Successful campaigns (ie, leading to policy adoption) tended to work closely with the local stakeholders and community, and built relationships with local law enforcement agencies and decision-makers from the start to increase support.

Wide-scale adoption of licencing systems may be enhanced by scientific evidence on their effectiveness. Further research may evaluate policies that are implemented, both within Europe and in other parts of the world. Past experiences with licencing systems, or any new initiatives, may be used as 'natural experiments' to examine how licencing may contribute to tobacco control. We may also learn from past experiences how strategies

\section{What this paper adds}

What is already known on this subject

- Tobacco retailer licencing has been recommended as an effective tobacco control strategy.

- In most European countries, however, retailers do not need a licence to sell tobacco products. What important gaps in knowledge exist on this topic

- Until now, there is no systematic overview of the potential benefits of licencing systems, methods of licencing and barriers and success factors in adoption of licencing systems in European countries.

- Such an overview could stimulate a discussion on the adoption of tobacco retail licencing in Europe.

\section{What this paper adds}

- Tobacco retail licencing may contribute to smoking prevention through improved enforcement of existing point-of-sale tobacco control policies, through reductions in the number of tobacco retail outlets, and through denormalisation of tobacco.

- The effectiveness of licencing methods may depend on the cost of licences and the criteria for purchasing and retaining a licence, such as minimum distance to schools or to other retailers.

- Framing tobacco retailer licencing within a child protection framework may help generate the strong political and public support needed to effectively adopt licencing systems. of adoption may be optimised, taking into account the perspectives and potential influence of different interests groups. ${ }^{38}$

\section{CONCLUSION}

Tobacco retailer licencing is a promising step toward more effective monitoring of the retail environment and denormalisation of smoking. It facilitates better enforcement of policies against selling tobacco products to youth and appears to contribute to reductions in the ubiquity of tobacco retailers. Licencing in Europe, and potentially in other policy contexts as well, may be most likely to be effective in countries with a focus on child protection and high level of political will for tobacco control, as this facilitates the adoption of licencing systems with a clear public health goal.

\section{Twitter Marc C Willemsen @Marc_Willemsen}

Contributors PAWN and MAGK studied the literature, PAWN drafted the manuscript and MAGK wrote the final manuscript. MCW and AEK were closely involved in the interpretation of the findings and provided critical input on the manuscript. AEK supervised the process.

Funding The authors have not declared a specific grant for this research from any funding agency in the public, commercial or not-for-profit sectors.

\section{Competing interests None declared.}

Patient consent for publication Not required.

Provenance and peer review Not commissioned; externally peer reviewed.

Open access This is an open access article distributed in accordance with the Creative Commons Attribution Non Commercial (CC BY-NC 4.0) license, which permits others to distribute, remix, adapt, build upon this work non-commercially, and license their derivative works on different terms, provided the original work is properly cited, appropriate credit is given, any changes made indicated, and the use is non-commercial. See: http://creativecommons.org/licenses/by-nc/4.0/.

\section{ORCID iDs}

Mirte A G Kuipers http://orcid.org/0000-0002-8133-1834

Marc C Willemsen http://orcid.org/0000-0001-9387-592X

\section{REFERENCES}

1 Chapman S, Freeman B. Regulating the tobacco retail environment: beyond reducing sales to minors. Tob Control 2009;18:496-501.

2 Wooten $\mathrm{H}$, McLaughlin I, Chen L. Zoning and licensing to regulate the retail environment and achieve public health goals. Duke FL \& Soc Change 2013;5:65.

3 Ackerman A, Etow A, Bartel S, et al. Reducing the density and number of tobacco retailers: policy solutions and legal issues. Nicotine Tob Res 2017;19:133-40.

4 World Health Organization. Protocol to eliminate illicit trade in tobacco products. Geneva: World Health Organization, 2013. https://www.who.int/fctc/protocol/illicit_ trade/protocol-publication/en/

5 Monshouwer K, Verdurmen J, Ketelaars T. Points of sale of tobacco products: synthesis of scientific and practice based knowledge on the impact of reducing the number of points of sale and restrictions on tobacco product displays. Utrecht: TrimbosInstituut, 2014. Available: https://www.trimbos.nl/docs/fc34ad60-2cec-4100-8a9fdc49bb88373e.pdf [Accessed 11 Dec 2020].

6 Robertson L, Marsh L, Edwards R, et al. Regulating tobacco retail in New Zealand: what can we learn from overseas? N Z Med J 2016;129:74-9.

7 Coxe N, Webber W, Burkhart J, et al. Use of tobacco retail permitting to reduce youth access and exposure to tobacco in SANTA Clara County, California. Prev Med 2014;67 Suppl 1:S46-50.

8 Caceres L, Chaiton M. Hungary: state licensing for tobacco outlets. Tob Control 2013;22:292-3.

9 Bowden JA, Dono J, John DL, et al. What happens when the price of a tobacco retailer licence increases? Tob Control 2014;23:178-80.

10 . Reducing tobacco retail density in San Francisco: a case study Bright Research Group for the San Francisco Tobacco-Free project; 2016. https://sanfranciscotobaccofreep roject.org/wp-content/uploads/Retail-Density-Case-Study-1.27.16-FINAL-to-TFP.pdf [Accessed 23 Dec 2020].

11 Lawman HG. The Pro-Equity potential of tobacco Retailer licensing regulations in Philadelphia. Am J Public Health 2019;109:427-8.

12 Finan LJ, Lipperman-Kreda S, Abadi M, et al. Tobacco outlet density and adolescents' cigarette smoking: a meta-analysis. Tob Control 2018:tobaccocontrol-2017-054065.

13 Nuyts PAW, Davies LEM, Kunst AE, et al. The association between tobacco outlet density and smoking among young people: a systematic methodological review. Nicotine Tob Res 2019. doi:10.1093/ntr/ntz153. [Epub ahead of print: 21 Aug 2019]. 
14 Pulakka A, Halonen Jl, Kawachi I, et al. Association between distance from home to tobacco outlet and smoking cessation and relapse. JAMA Intern Med 2016;176:1512-9.

15 Cantrell J, Pearson JL, Anesetti-Rothermel A, et al. Tobacco retail outlet density and young adult tobacco initiation. Nicotine Tob Res 2016;18:130-7.

16 Pearce J, Rind E, Shortt N, et al. Tobacco retail environments and social inequalities in individual-level smoking and cessation among Scottish adults. Nicotine Tob Res 2016:18:138-46.

17 Cole AG, Aleyan S, Leatherdale ST. Exploring the association between e-cigarette retailer proximity and density to schools and youth e-cigarette use. Prev Med Rep 2019;15:100912.

18 Pérez A, Chien L-C, Harrell MB, et al. Geospatial associations between tobacco retail outlets and current use of cigarettes and e-cigarettes among Youths in Texas. J Biom Biostat 2017;8. doi:10.4172/2155-6180.1000375. [Epub ahead of print: 1810 2017].

19 Astor RL, Urman R, Barrington-Trimis JL, et al. Tobacco retail licensing and youth product use. Pediatrics 2019;143:e20173536.

20 Malone RE, Grundy Q, Bero LA. Tobacco industry denormalisation as a tobacco control intervention: a review. Tob Control 2012;21:162-70.

21 Finland Ministry of social Affairs and health. tobacco act (549/2016; amendments up to $1374 / 2016$ included) 2016

22 Valiente R, Sureda X, Bilal U, et al. Regulating the local availability of tobacco retailing in Madrid, Spain: a GIS study to evaluate compliance. Tob Control 2019;28:325-33.

23 Démarche Devenir débitant de tabac (conditions pour être débitant de tabac)Douane Française. Available: https://www.douane.gouv.fr/demarche/devenir-debitant-detabac-conditions-pour-etre-debitant-de-tabac [Accessed 11 Dec 2020].

24 Cova P. The Italian tobacco industry: a state monopoly. PSL Quarterly Review 1947;1.

25 Origen del comisionado para el mercado de tabacosMinisterio de Hacienda. Available: https://www.hacienda.gob.es/es-ES/Areas\%20Tematicas/CMTabacos/Paginas/ ORIGEN-DEL-COMISIONADO-PARA-EL-MERCADO-DE-TABACOS.aspx [Accessed 20 Aug 2020].

26 . Decreto Ministeriale 38/2013 del 21 Febbraio 2013. Adozione del regolamento recante disciplina della distribuzione e vendita dei prodotti da fumo. Agenzia Dogane Monopoli; 2013
27 Robertson L, Marsh L, Hoek J, et al. Regulating the sale of tobacco in New Zealand: a qualitative analysis of retailers' views and implications for advocacy. Int J Drug Policy 2015;26:1222-30

28 Kok L, Kroon L, Meerkerk G-J. Beperken van Het aantal verkooppunten tabak. Verkenning beleidsopties. Amsterdam: SEO Economisch Onderzoek, 2020.

29 World Health Organization. European tobacco use: trends report 2019. Geneva: WHO, 2019.

30 Nuyts PAW, Hewer RMF, Kuipers MAG, et al. Youth access to cigarettes across seven European countries: a mixed-methods study. Nicotine Tob Res 2020;22:1989-96.

31 Norwegian Ministry of Health and Care Services. A tobacco-free future: national strategy for tobacco control 2013-2016. Available: https://www.regjeringen.no/ contentassets/818bac68f5994a9181a0251032a8685a/national_strategy_tobacco. pdf [Accessed 11 Dec 2020].

32 Kuijpers TG, Willemsen MC, Kunst AE. Public support for tobacco control policies: the role of the protection of children against tobacco. Health Policy 2018;122:929-35

33 Willemsen MC, Walters BH, Kotz D, et al. Recommendations on how to achieve tobacco-free nations in Europe. Tob Prev Cessat 2019;5:24.

34 Action of Smoking and Health. Counter arguments - how important is tobacco to small retailers? London: action on smoking and health, 2016. Available: https://ash. org.uk/information-and-resources/reports-submissions/reports/counter-argumentshow-important-is-tobacco-to-small-retailers/ [Accessed 11 Dec 2020]

35 Willemsen MC. Tobacco control policy in the Netherlands: between economy, public health, and ideology: Springer 2018.

36 McDaniel PA, Malone RE. "People over profits": retailers who voluntarily ended tobacco sales. PLoS One 2014;9:e85751.

37 Satterlund TD, Treiber J, Haun S, et al. Evaluating local policy adoption campaigns in California: tobacco retail license (TRL) adoption. J Community Health 2014;39:584-91.

38 Kuijpers TG, Kunst AE, Willemsen MC. Policies that limit youth access and exposure to tobacco: a scientific neglect of the first stages of the policy process. BMC Public Health 2019;19:825. 